\title{
LAS ALPUJARRAS
}

\section{(Estudio de una Comarca: sus pueblos, sus hombres y sus costumbres)}

352.071

por

\section{Gumersindo Guerra-Librero y Arroyo}

Técnico Urbanista

SUMARIO: I. LA COMARCA: 1. SITUACIÓN. 2. LfMITES Y EXTENSIÓN. 3. Clima, vientos y lluVia.-II. LOS PUEBLOS.-III. LA VIVIENDA: 1. Aspecto. 2. Materiales. 3. Distribucion y ampliaCIÓN DE las viviendas. 4. TERRADOS, aZoteas, galerfas, balcones volados. 5. ORIENTACIÓN. 6. SEMEJANZAS. - IV. LA HISTORIA: 1. Primeros pobladores. 2. Griegos, Romanos y visigodos. 3. ARABES. - V. LOS HOMBRES DE LAS ALPUJARRAS: 1. COMO SON loS ALPUJARREÑos. 2. FolkLoRE: A) Fiestas de moros y cristianos. B) Rosarios de animas. C) Bailes. D) Trobos. E) Música. 3. Del aislamienlo al turismo.-VI. GEOGRAFIA ECONOMICA: 1. LA PROPIEDAD DE LA TIERRA. 2. AGRICULTURA, FRUTICULTURA Y BosQUeS: A) Agricultura. B) Fruticultura. C) Bosques. 3. VIDA DE Montaña. 4. El RIEgo. 5. Ganaderfa y Pastoreo. A) Ganaderia. B) Pastoreo. 6. CAZA y PESCA: A) Caza. B) Pesca. 7. Industria. 8. PROBLEMA DE EMIGRACIÓN.-VII. EXCURSIONES PARA CONOCER LA COMARCA.-VIII. BIBLIOGRAFIA. 


\section{LA COMARCA}

\section{Situación}

Hasta hace poco no sabía yo cómo eran las Alpujarras ni dónde caían, y como a mí les ocurre a una gran mayoría de españoles. Un amigo me habló de esa histórica Comarca y despertó mi interés por conocerla. En varias ocasiones la he visitado desde entonces.

Todos hemos oído hablar de Sierra Nevada. Esta sierra tiene dos vertientes. La que da al Norte es un lanchar sin vegetación, por lo que resulta una cara gris y fea. Pero la vertiente que da al Sur tiene bosques, agua, luz y aire purísimo. En esta vertiente caen las Alpujarras. En las Alpujarras hay cultivos que llegan a alcanzar una altura sobre el mar que supera los mil quinientos metros. Y es que la estructura de esta cara de Sierra Nevada ha hecho posible terraplenarla. Por esos cultivos terraplenados discurren las aguas, regando los términos de más de setenta pueblecitos y aldeas.

La Comarca alpujarreña está formada por una depresión de unos cincuenta kilómetros por la que discurre el río Grande de Adra, entre la Sierra Nevada, al Norte, y la Contraviesa y el Mediterráneo, al Sur. Otros ríos de la Comarca son el Guadalfeo, que va al Oeste, y el Andarax, al Este. Las Alpujarras están modeladas por lo geográfico, pero deben mucho a la historia. Es una Comarca con una aureola legendaria, como luego veremos.

En los pueblecitos alpujarreños he oído hablar de Alpujarras altas y bajas. También or lo mismo en las Hurdes. La parte alta de la Comarca alpujarreña es escarpada y angosta, como encajonada entre las crestas más elevadas de Sierra Nevada, y parece centrarse en torno a Orgiva. La otra zona, baja y oriental, es amplia y abierta, de aspecto más meridional, y su núcleo más importante es Ugíjar. También en esta parte las montañas se ven cubiertas de nieve hasta el mes de julio.

\section{LIMITES Y EXTENSION}

El límite sur de las Alpujarras es la costa del Mediterráneo, entre los cabos Sacratif y de las Entinas. Abarca la Comarca unos 80 kilómetros de Este a Oeste y 30 de Norte a Sur.

La Biblioteca de Autores Españoles publicó una edición de la 
obra de Juan RuFo titulada La Austriada (por don Juan de Austria); en su canto primero se puede leer:

$$
\begin{aligned}
& \text { «... unos y otros en casales } \\
& \text { de la vega y del valle se arraigaron } \\
& \text { y muchos en las villas de la sierra } \\
& \text { que llaman Alpujarra en esta tierra, } \\
& \text { son diecisiete leguas de largura, } \\
& \text { que miran al levante y al poniente } \\
& \text { y extiéndese con once por la anchura } \\
& \text { entre Granada y aguas de Tridente...» }
\end{aligned}
$$

En las Alpujarras, aparte de la Sierra Nevada, se incluyen otros tres macizos de sierras sobre la costa: las de Lujar y Contraviesa, al Oeste, y la de Gádor, al Este. Esta parte tiene playas y campos a ras del mar, mientras el resto está formado por laderas y barrancos entre medias de tres ríos, con múltiples torrentes y ramblas, la mayor parte del año, que forman remansos como vegas, con frondosa vegetación. Dichos ríos son: el Grande de Cadiar, que sale por Occidente para desembocar por las playas de Motril; el Grande de Adra, que corre de Norte a Sur hasta cerca de esta ciudad, y el de Andarax, que va hacia el Este, desembocando en el Almería.

Límite de la Alpujarra por este lado es la caída de las sierras Nevada y de Gádor frente a Mondújar, sobre la margen del río de Gergal, a la parte Sur, y una derivación de la sierra de Gádor que alcanza la ya citada punta de Las Entinas. A Occidente quedan fuera de ella el valle de Lerín y la sierra de las Guájaras, pasando sus linderos por el término de Motril, por la cumbre de la sierra de Lújar, que muere en el cabo Sacratif y desagua más allá del río de Cádiar, con nombre de Guadalfeo. Sobre su margen derecha avanza una última estribación de la Sierra Nevada, permitiendo estrecha salida a la vega de Orgiva, y allí acaba la Comarca alpujarreña, que antes abarcó a Lanjarón, protegida desde el camino de Granada por el Barranco de Tablate, con su histórico puente famoso, que fue siempre la puerta natural para entrar en la Comarca.

\section{Clima, vientos y lluvia}

El clima es muy variado en las Alpujarras, pues tiene costas templadas y montañosas partes nevadas, $y$, como consecuencia de esto, la variedad de productos agrícolas y forestales es grande. 
Yo he visto a los labradores alpujarreños aventando sus cosechas de cereal durante las noches de verano. Aprovechaban el vientecillo que empieza al atardecer y llega al amanecer. Esto era en la parte alta, y era curioso ver a las figuras iluminadas por la luz de los faroles.

Los labradores me dijeron que en las partes bajas la brisa marina suele soplar durante el día y la noche con gran fuerza.

Aunque no he visitado las Alpujarras en el invierno, he leído en BRENAN lo siguiente: "En enero o febrero el viento se lanza ladera abajo con la fuerza de un huracán, llevando copos de nieve en franjas horizontales y maltratando olivos y chimeneas». Esto puede leerse en el libro Al sur de Granada.

La lluvia suele ser recibida por los alpujarreños con alborozo, pero cuando viene del Oeste puede ser peligrosa, porque dura a veces días enteros, llegando a las ramblas cuando están resecas, desbordándolas, hundiendo puentes, arrasando sembrados y destruyendo a su paso casas y caminos. Cuando estuve en las Alpujarras la vez anterior me contaron escenas espeluznantes de la riada de Albuñol el 4 de setiembre de 1974, que costó más de sesenta vidas humanas. He visto en medio de la Rambla de Albuñol una piedra colosal que había sido arrastrada por la corriente desde la montaña.

Cuando las tormentas se prolongan en las Alpujarras sus efectos suelen ser desastrosos. Antes había también un problema en muchas viviendas: las goteras. Hoy los alpujarreños lo han resuelto gracias a su ingenio y a las técnicas modernas, colocando debajo de la "launa» (luego diremos lo que es esto) fuertes láminas de plástico.

\section{LOS PUEBLOS}

1. Albondón.

2. Albuñol.

3. Bérchules.

4. Bubión.

5. Busquístar.

6. Cádiar.

7. Cáñar.

8. Capileira.

9. Carataunas.

10. Cherín.
11. Jorairátar.

12. Juviles.

13. Lanjarón.

14. Lújar.

15. Mairena.

16. Mecina-Bombarón.

17. Murtas.

18. Narila.

19. Orgiva.

20. Pampaneira. 
21. Pitres.

22. Pórtugos.

23. Torviscón.

24. Trevélez.

25. Turón.
26. Ugijar.

27. Válor.

28. Yátor.

29. Yegen.

1. Albondón. Situado en una ladera de la Contraviesa, a cinco kilómetros de Albuñol.

2. Albuñol. Es un pueblo rico y se considera de costa, aunque el mar está a unos cuatro kilómetros. La Rábita es como el puerto de Albuñol, al que se une por la Rambla. La Rábita tiene más de 200 casas. Desde Albuñol se ve el Mediterráneo con sus barcos. Le pregunté a un comerciante por qué Albuñol no parecía una población marítima, y me hizo ver que sí lo era, aunque disimuladamente. Me dijo que el peligro de los corsarios turcos y de los moros hizo que Albuñol no estuviera en la misma playa.

Hoy, Albuñol es uno de los principales centros de riqueza de las Alpujarras, pues es un pueblo industrial, comercial, agrícola, marítimo y minero.

Pasó mucho tiempo después de la expulsión de los moriscos casi despoblado. Luego fue creciendo, y en tiempos de Alarcón, que escribió un libro sobre las Alpujarras, tenía 8.000 habitantes, repartidos entre la villa y diez aldeas, muchos cortijos y La Rábita. Más de 1.700 casas, y de ellas, 800 diseminadas por los campos.

En octubre de 1973 la famosa riada que tantas vidas costó dejó a muchas personas sin trabajo, por lo que más de ochenta familias (unas 450 personas) tuvieron que emigrar, muchos de ellos a Cataluña; otros, a pueblos cercanos, como Roquetas. Ese éxodo era la expresión de una desesperanza, un fenómeno que allí era casi desconocido, pues se producía gran cantidad de frutas tempranas, y una hectárea de aquellas tierras de la Rambla daba de comer a tres familias, y con la riada se hicieron imposibles aquellos cultivos durante largo tiempo, por haber arrastrado al mar las buenas tierras ya preparadas.

En Albuñol hay agricultura y pequeñas industrias: mosaicos, cemento, partidera de almendras, frutos secos (la riada se llevó su maquinaria) y la construcción.

3. Bérchules. El nombre le viene de los antiguos vergeles moriscos. Su paisaje resulta alegre. Sombreado por una loma que lla- 
man de Sortes, en él se cultivan abundantes árboles frutales, y una industria; se trata de una fábrica de alfombras típicas alpujarreñas, que quiere decir moriscas.

4. Bubión. A 1.331 metros sobre el nivel del mar. Es un pueblo de origen visigótico, donde sus 700 habitantes viven en 200 edificios y cultivan cereales, tubérculos y leguminosas en tierras escalonadas o paratas, bien regadas. En su término abundan los castaños.

En el paisaje urbano, donde predomina el gris de las lajas y la launa de los tejados, se destaca la iglesia, cubierta de tejas de barro cocido.

Bubión tiene una historia trágica, pues durante la rebelión los moriscos mataron a muchos cristianos en la placita que hoy se llama de los Mártires.

5. Busquistar. Está a diez kilómetros de Trevélez, en un término en que abundan los olivos. Se distinguen dos barrios, y en su término se halla ubicada la mina de hierro del Conjuro.

6. Cádiar. Es una villa próspera, situada sobre el río que hacia el Oeste va a dar al mar, en Motril, marcando el punto central de la Alpujarra. Su aspecto es de lo más pintoresco que pueda darse. Tiene 2.354 habitantes. Cádiar fue teatro del drama de MarTínez DE LA ROSA y lugar donde fue coronado oficialmente Aben-Humeya.

La villa de Cádiar, situada sobre una vertiente en lo más montañoso de la Alpujarra, lo que no impide que los terrenos que la rodean sean muy fértiles, se recomienda por la pureza de sus aires y de sus aguas, y es hoy un pueblo de reducido vecindario, agrupado alrededor de una iglesia situada en lo más alto y compuesto por varios barrios.

Pero en el año 1568 era otra cosa. Sólo habían pasado setenta y seis años desde la conquista de Granada. Aquello había determinado el apogeo, la riqueza no sólo de Cádiar, sino también de las demás villas y lugares de las Alpujarras. Esto se explica porque al trasladarse el rey Boabdil a Andarax, después de la toma de Granada por los Reyes Católicos, llevó consigo, a aquel destierro donde estuvo dos años, gran parte de su corte y de sus caballeros, mientras otros muchos y ricos musulmanes, con sus familias, esclavos y tesoros, se habían trasladado desde Granada a ésta o a la otra villa de las Alpu- 
jarras, pretendiendo ocultarse de la vista de los vencedores. "Tales musulmanes -escribe FERNÁNDEZ Y GoNZÁLEZ-, acostumbrados a la molicie y riqueza de sus alcázares y a la frescura y frondosidad de los jardines que habían dejado en la ciudad perdida, embellecieron, para hacer más cómoda su residencia en ellas, y aumentaron la población y la riqueza de las villas a que se habian acogido».

«Cádiar había sido una de las villas más favorecidas por esta especie de inmigración. Muchas familias poderosas se avecindaron en ella y con una rapidez maravillosa fueron desapareciendo las casas pobres y antiguas para dar lugar a otras más bellas y mejor proporcionadas. Construyéronse aljibes; convirtiéronse en amenos cármenes las laderas de la montaña; estableciéronse en sus plazas mercaderes; creció el tráfico y el dinero, y la antes insignificante villa se convirtió en una población importante, rica, populosa y considerada".

Por ello el Capitán general de la Costa y Reino de Granada situó en ella un presidio de soldados y un Corregidor. Había también un beneficiado en la iglesia parroquial de la villa.

7. Cáñar. Llamado el Balcón de la Alpujarra, está situado sobre Orjiva. Se dice que Felipe II le concedió el título de villa por haberse hecho prisionero en su término a Aben-Farax, destacado cabecilla morisco.

8. Capileira. A más de 1.500 metros sobre el nivel del mar, éste es el segundo pueblo de España por su altitud, y resulta ser, por su luz y colorido, uno de los más bellos de la Comarca alpujarreña. Sus blancas calles encaladas y sus balcones floridos le prestan un encanto especial, hasta tal punto que este pueblecito podría destacarse como zona turística de verano e invierno, pues en algunos aspectos es mejor que Lanjarón. Su clima es estupendo durante casi todo el año y tiene una zona edificable de gran belleza paisajística y abundantes aguas.

En medio de sus edificios con terrados planos de launa gris se destaca la iglesia, cubierta con tejas. Hay en la iglesia una imagen de Nuestra Señora de la Cabeza que, según tradición, fue donada por los Reyes Católicos.

9. Caratauna. Es una de las viejas alcarías de Orgiva, de la que dista seis kilómetros por carretera. 
En sus proximidades, cerca del cruce con Soportújar, se hallan las minas de Nuestra Señora de las Angustias, y más arriba, la ermita del Padre Eterno, Patrono de esta zona del valle. De esta ermita parte un camino forestal construido por ICONA que nos lleva a uno de los parajes más bellos de esta Comarca, en donde nacen los ríos Chico y Lanjarón. En sus frondosos bosques y en su zona más alta la fauna es abundante, destacando ejemplares de capra montesa.

También en las proximidades de la ermita del Padre Eterno están las canteras de donde se extrae la launa para la edificación de los famosos terrados alpujarreños.

10. Cherin. Con más de 900 habitantes, a orillas del río Adra, que allí se llama río Cherín.

11. Jorairátar. Aldea en declive, semiderruida, a la sombra del peñón de su nombre. Su riqueza fue el aceite y los higos.

12. Juviles. Blanco caserío presidido por un templo de muros grises. Tuvo en tiempos moriscos y posteriormente importancia por su producción de seda y sus industrias de muebles y joyas, pero BRENAN la vio ya como un villorrio decadente.

13. Lanjarón. Conocido balneario para las dolencias del reuma y del hígado. Está a la entrada de la Alpujarra.

En verano el mundo de Lanjarón es abigarrado y multicolor, formado por españoles y marroquíes que acuden en número de hasta cinco mil. Los gitanos venden allí "objetos típicos de las Alpujarras", aunque estos objetos están fabricados en el Albaicín granadino.

Son famosos sus balnearios de aguas minero-medicinales. Hay varias fuentes que se utilizan en la actualidad: Capuchina, Capilla, el Salado, Salud y Fonte Forte.

Sus aguas están indicadas en las enfermedades de la vesícula biliar; para artríticos y uricémicos; para diabetes, anemia, trastornos menstruales y del desarrollo; baleoterapia; sedante del aparato digestivo y agua carbónica de mesa.

Lanjarón es doble. Hay una ciudad de los hoteles, y a continuación está el viejo pueblo, en el que ya se empiezan a ver las terrazas de launa que luego será la característica general del caserío alpujarreño.

Hace medio siglo, Brenan vio a Lanjarón como una ciudad extendida cual una balaustrada a lo largo de una escarpada ladera. 
Escribía: «Los veranos son cálidos y tiene hoteles para los que acuden a sus balnearios a curar su reumatismo y dolencias del riñón».

14. Lújar. Con buenas fuentes con surtidores varios, a pesar de que en su tierra calcárea sólo crece un monte bajo muy enteco, Lújar tiene buenos vinos y jamones. En este pueblo antiguo hay una calle denominada de Aben-Humeya, y en ella hemos visto un edificio que dicen está construido en el solar que ocupó la casa en que fue asesinado Aben-Humeya. La casa está enlosada con losas antiguas, tiene un patio de columnas de madera y en su fachada hay esculpida una cabeza. Me dijeron que era la cabeza de un morisco. Como también me afirmaron que aquella casa fue la corte de AbenHumeya durante su corto reinado.

15. Mairena. Es el pueblo más alto de la parte este de Sierra Nevada. Gran número de sus habitantes son gitanos. Hasta hace poco era una aldea muy aislada.

16. Mecina-Bombarón (o sea del Buen Varón). Muchas de sus casas están diseminadas entre bosques y castaños. El pueblo aparece parcialmente encalado. Hay buenas manzanas y patatas.

17. Murtas. Creo que es un pueblo mayor que la cabeza de su partido, que era Ugijar. Tiene muchos cortijos y caseríos, que aumentan el censo de población. Es rico en vino y almendras. En tiempos antiguos era famoso por su arriería, que era la más activa y numerosa de la Alpujarra. Sus aguardientes también tenían mucha fama en la Comarca.

a Alarcón le pareció una ciudad austera, como si fuera de Castilla la Vieja y no de las Alpujarras; así, escribió que Albuñol era un pueblo moro, y Murtas, cristiano.

18. Narila. Hay en Narila un templo fundado por Felipe el Hermoso y doña Juana la Loca. El retrato de dichos reyes está en la citada iglesia.

19. Orgiva. El pueblo más importante de las Alpujarras está situado en un llano en donde se juntan dos ríos: el llamado Grande de Caiar y el Chico, que baja directamente de Sierra Nevada.

Orgiva tiene cuatro barrios algo apartados. Uno de ellos se llama Albacete. 
La pequeña historia. Dominando Orgiva desde lo alto de un cerro está la ermita de San Sebastián. Mucho antes de la llegada de los árabes allí existía una fortaleza visigoda, según aseguran algunos autores, como Simonet y CARRAScosa (el primero, en su libro Descripción del Reino de Granada bajo la dominación de los nazaritas, que publicó en Madrid en 1800; hay una edición del año 1934. CARRASCOSA, en $A$ las puertas de las Alpujarras), que tomaron datos de autores árabes, para quienes en tiempos visigodos había allí un castillo. Al pie de este castillo había un pequeño llano que se llamó Albacete de Orgiva (Albasatch, en árabe, quiere decir llanura).

A principios del siglo XIII los árabes hicieron a Orgiva cabeza de un distrito o taha que comprendía muchas alcarias; algunas, ya desaparecidas; otras, como Cáñar, Soportújar y Caratauna, se conservan.

En Orgiva residía el jefe de la taha y de su autoridad dependían las citadas alcarías.

Orgiva actual. Orgiva tiene una buena situación; gracias a ello se ha convertido en el mejor núcleo de comunicaciones entre las tres zonas alpujarreñas: la Alta, la Media y la Baja. Desde Orgiva es más fácil conocer las Alpujarras, lo que favorece el turismo.

Orgiva cuenta con más de cuatro mil habitantes, y con todas sus entidades alcanza unos siete mil. Tiene este pueblo muchos comercios de comestibles, panaderías, frutas y verduras, tejidos, calzado y vino al por mayor. He contado unos cuarenta, a los que había que agregar otros, como droguerías, ferreterías, abonos, mercerías, librerias, etc.

Orgiva tiene Ayuntamiento, Juzgado, Registro de la Propiedad, Notaría, Agencia del Instituto Nacional de Previsión, Estafeta de Correos, Compañía de Guardia Civil, sucursales de Bancos, Caja de Ahorros y Monte de Piedad de Granada, etc.

Cuenta también con varias Entidades culturales y recreativas y escuelas, donde prestan servicios más de cuarenta profesores de Educación General Básica.

En su buena Biblioteca Hurtado de Mendoza he pasado horas dedicado a este trabajo, siendo muy bien atendido por el personal de la misma.

La fuente principal de riqueza de Orgiva y su tierra ha sido la agricultura, razón de los muchos poblados que se levantan en valles y laderas. Cuando haya suficiente y bien regulada energía eléctrica se crearán en las Alpujarras nuevas industrias; se podrán elaborar pastas alimenticias, o quesos, o embutidos; se podrá fundir el hierro, 
el cobre, el plomo y otros minerales, y podrá refinarse el aceite y crearse ferreterías y maquinarias.

No quiere decir que en Orgiva no haya energía eléctrica. En la parte sur de la ciudad hay una subestación térmica. EI INI construyó varias centrales térmicas en el litoral de Cádiz a Cartagena, y en Orgiva se emplazó la mencionada subestación. En ella se recibe la energía de Málaga y Almería a 132 kilovatios y, por mediación de aparatos de sincronismo, se unifica la producción de ambas centrales, pudiendo enviar flúido eléctrico, indistintamente, a los puntos de producción.

En una alcaría próxima a Orgiva, sobre la Rambla, se ha abierto un profundo pozo artesiano del que actualmente se surte esta ciudad, que antiguamente recibia sus aguas de la acequia procedente de la parte alta del barranco del Poqueira, que aún existe.

20. Pampaneira. Quiere decir tierra de los pámpanos, y efectivamente allí hay vides y mucha gente cultiva viñas en las tierras que poseen hacia el término de Pitres. En el barranco de Poqueira se ven tres pueblecitos blancos: Pampaneira, Bubión y arriba, hacia el Veleta, Capileira. Uno de los problemas de estos pueblos es la necesidad de una carretera que les comunique con el Veleta. Por ello vienen luchando los Alcaldes de esos pueblos. Otro problema de Pampaneira es la emigración, que ha privado de brazos al campo y ha hecho que muchas paratas del barranco se vean abandonadas. En estas tierras del Poqueira abundan los castaños.

La iglesia de Pampaneira tiene en el dintel de su puerta un escudo y en su interior un bello altar dorado y un buen artesonado mudéjar.

Pampaneira ha sido declarada recientemente por el Consejo de Europa zona de permanente interés turístico internacional. Sus calles y balcones están por este motivo embellecidos con motivos decorativos.

21. Pitres. Está a medio camino entre Orgiva y Ugíjar. En una aldea llamada Capilerilla y también Capileira de Pitres, a medio kilómetro de la villa, existían los arcos y los muros de una iglesia visigótica que los moriscos habían quemado (1568). Aquella reliquia del primitivo cristianismo alpujarreño fue demolida para aprovechar sus piedras en la reconstrucción de la iglesia de San Roque, que tiene una airosa torre renacentista. 
Esta barbaridad no la hicieron esta vez los moriscos, sino Regiones Devastadas, que, en ocasiones tales, debería haberse llamado «devastadoras».

En Pitres me enteré de algunas palabras como taha, rábita, macaber. La Comarca se llama Taha de Pitres, todavía como en tiempos moriscos. Es una Comarca diminuta entre dos ríos con nombres que evocan tragedia: el río Bermejo y el río Sangre.

Pitres tenía categoría de villa y ya en tiempos moriscos contaba con tres barrios.

22. Pórtugos. Situado en la vertiente sur del Mulhacén, cuenta este pueblo con casi 200 edificios y 870 habitantes. Su iglesia, construida sobre la sillería de una vieja mezquita musulmana, conserva el viejo artesonado mudéjar. Sus calles están bien arregladas. Hay agua en sus casas y saneamiento. Encantado por la simpatía de sus habitantes, indagué sobre sus pobladores. Un profesor de EGB me lo aclaró.

El rey Felipe II, después de la expulsión de los moriscos, mandó repoblar el pueblo. Llegaron familias de Jaén, de Cuéllar, de Llerena, de Osuna, de Calzadilla, Calzada de Calatrava, Puebla de Montalbán y Bayona. Cincuenta y seis familias, andaluces, castellanos de ambas Castillas, gallegos y extremeños.

El campo de Pórtugos produce cereales, legumbres, tubérculos y frutales. No faltan los castaños.

23. Torviscón. Es un pueblo grande con cuatro barrios situado en una vertiente de la Contraviesa. Tiene rambla. Antiguamente gozó de importancia por ser residencia de Corregidores y cabeza de un Juzgado de Primera Instancia. Tuvo cerca de 2.500 habitantes, con más de ochenta cortijos y caseríos.

24. Trevélez. ¿Quién no ha oído hablar de los jamones de Trevélez? Su bondad es debida seguramente a un clima frío y seco y a la altitud del pueblo: 1.700 metros sobre el nivel del mar. Uno de los núcleos urbanos más altos de la Península y desde luego de Europa. Por eso allí se dice que oyen cantar a los ángeles.

Trevélez aparece escalonado en tres barrios: Bajo, Medio y Alto, cada uno de los cuales tiene 100 metros de desnivel con respecto al otro. Las calles, estrechas y pinas, están asfaltadas en su mayoría; pocas son las que quedan como antiguamente empedradas con lajas puestas de canto, como en gran número de pueblos alpujarreños. 
He observado en Trevélez, como en muchos pueblecitos de esta Comarca, una abigarrada distribución de ventanucos.

Trevélez tiene porvenir turístico, por su proximidad al Mulhacén.

Sería ideal construir un teleférico que salvara el desnivel de unos 1.200 metros que hay hasta el Chorrillo.

A los ingleses, que vienen desde Orgiva en mulos y caballerías, le gusta mucho hacer excursiones desde Trevélez al Mulhacén y a Jerez del Marquesado.

Trevélez, con su pequeña vega, con su río truchero, con el Mulhacén nevado como telón de fondo, parece un sueño y podría transformarse, con los mejoramientos adecuados, en un pueblo de vida paradisíaca, que mostrara al visitante un pintoresquismo sano, alegre y productivo.

25. Turón. Con más de 2.000 habitantes, es un pueblo alegre, en cuyo término se producen higos, almendras, trigo y cebada. Antes se explotaba en su término una mina de plomo.

26. Ugijar. Hace más de un siglo, en 1872, Pedro Antonio DE AlarCón escribió La Alpujarra. Entonces consideraba a Ugíjar la población más cualificada del territorio alpujarreño.

Cuando el escritor inglés Brenan vivía en Yegen había en Ugijar una fábrica de hilaturas de seda, establecida por industriales de Lyon (Francia), que dio trabajo a doscientas operarias y revivió la cría del gusano de seda y de las moreras de que se alimentan.

BRENAN vio a Ugíjar como un lugar pequeño, limpio y hermoso, rodeado de naranjales; con la mayor parte de sus edificios techados con tejas; con varias tiendas y una plaza de mercado.

Otros autores lo han visto como la capital de las Alpujarras, y han hallado en ella cierto porte urbano.

Nosotros hemos hecho alto en Ugíjar ya casi saliendo de la Comarca. Hemos visitado su hermosa iglesia de ladrillo con molduras y hemos recorrido sus calles, con casas antiguas de pisos y balcones de aspecto nobiliario.

A la salida de Ugijar un hombre regaba unas huertas frondosas más allá del río. Bebimos agua, mientras el campesino nos hablaba de la antigua industria de la seda.

"Estos campos - nos dijo- producen todo lo que consumimos; hasta exportamos algún aceite. Tenemos varios molinos..." 
27. Valor. Entre dos frondosos barrancos se sitúan los cuatro barrios de este pueblo famoso por sus fiestas de moros y cristianos, que se vienen celebrando, desde los tiempos de la Reconquista, cada 14 de agosto, con gran afluencia de espectadores de dentro y fuera de la Comarca.

28. Yátor. Una aldea donde las mujeres y niños cultivaban la tierra, pues los hombres pasaban once meses cada año trabajando en las minas de plomo de Linares.

29. Yegen. El escritor inglés Brenan vivió en Yegen entre los años 1920 y 1934. Luego escribió su libro titulado Al sur de Granada, del que hemos tomado muchas notas.

Yegen está sumamente elevado por las andamiadas de la sierra, pero tan defendido del viento del Norte y tan a merced del sol y del ambiente de Africa que en él hallamos, entre brillantes chorros de nieve derretida, granados en flor, opulentos olivos y hasta naranjos. Encima del pueblo abundan los castaños, los nogales y las encinas, pero lo más notable de todo esto es un manantial de agua que hay a la subida del lugar, por la parte de Oriente. El agua es riquísima y brota casi un río al pie de una roca gigantesca. Así lo vio también Alarcón en su famoso viaje. Hace un siglo, Yegen contaba con 1.210 almas.

Para Brenan es uno de los pueblos más pobres entre los que tachonan la Alpujarra. Situado a gran altura sobre el nivel del mar, su ubicación resulta tan recóndita que, hasta que se construyó la actual carretera, el viaje desde Granada duraba dos días.

Cuando BRENAN vivió allí, Yegen gozaba de una situación mejor que la mayoría de los pueblos andaluces, pues todo el mundo ganaba lo suficiente para comer, aunque los niveles de alimentación, vestido y bienestar de las familias, a excepción de dos o tres privilegiados, eran más bajos que los de un campesino o un obrero inglés pobre. Pero nadie cambiaba la aldea por la ciudad, a menos que se viera obligado a hacerlo por algún infortunio.

Sin embargo, BRENAN escribía: "Me imagino que ha sido siempre una aldea en la que predominaron las familias humildes. Los bereberes la habían construido en cuatro barrios distintos, dos de los cuales quedaban a cierta distancia de los otros dos, con una mezquita situada en el lugar en que se encuentra la iglesia en la actualidad, en la única zona disponible de terreno llano». 
Hoy, al igual que muchas de las aldeas de Sierra Nevada, Yegen se compone de varios barrios, que hasta fecha bien reciente tenían cierta rivalidad.

La carretera que comunica Yegen con Ugijar constituye un paseo agradable de doce kilómetros de verdor, incluso en lo más tórrido del verano, pues todo su recorrido transcurre entre árboles frutales, olivos y viñas en emparrado, a cuyo cobijo crecen el trigo, el maíz y las judías.

En el término de Yegen abundan las higueras, moreras, granados y melocotoneros, así como los emparrados y bosquecillos de álamos, que es su árbol característico, y que pertenece a especies originarias de Virginia, de donde fueron introducidos durante el siglo pasado y utilizados para la construcción.

En la plaza del barrio medio de Yegen están la iglesia, el Ayuntamiento y un grupo escolar.

\section{LA VIVIENDA}

\section{ASPECTO}

El aspecto de las viviendas alpujarreñas ha cambiado poco con el tiempo. Después de la expulsión de los moriscos «allí no subsistieron del pasado -escribe GoMEz MORENO- sino las miserables casas de pizarra cubiertas con launa, agazapadas en las vegas o escalonadas en las vertientes".

Posteriormente, las casas se siguieron construyendo con la especial fisonomía morisca, y hasta las iglesias, heraldos de la nueva fe, salían de las manos de los alarifes, que dejaron su impronta en estos magníficos artesonados mudéjares, muchos de los cuales se conservan para admiración de propios y extraños.

Todavia hoy la generalidad de las viviendas son casas de muros de pizarra cubiertas de launa.

\section{Materiales}

Las «lajas» de pizarra son usadas por los alpujarreños como materia prima de la construcción. Los habitantes de esta Comarca son maestros en el arte de levantar paredes o «balates» sin usar barro ni argamasa, utilizando sólo piedra. 
3. DistRibución Y AMPLIACIÓN DE LAS VIVIENDAS

Las viviendas de las Alpujarras, aunque pobres en su mayoría, tienen el interior limpio y bien cuidado.

Las casas son de una o dos plantas. La escalera aparece en muchos muros exteriores de la vivienda, con objeto de poder subir al piso primero sin necesidad de pasar por el inferior, pues en éste se alojan los animales domésticos y también se halla la cocina.

La antigua casa morisca o dar se veía ampliada con la añadidura de varios cuerpos o edificios, de suerte que un conjunto constituía propiamente una unidad familiar o de linaje.

Después de la conquista de Granada los cristianos comenzaron a levantar viviendas más amplias, pues las de los moros eran pequeñisimas, con habitaciones reducidas, llenas de recovecos y sucias por fuera, aunque muy limpias en su interior.

Quienes visiten los núcleos mayores de la Comarca alpujarreña, como Ugijar, por ejemplo, podrán ver mansiones de un estilo muy característico.

En Pampaneira y en otras aldeas más pequeñas se siguen edificando en nuestros días casas de terrados, que prestan a estos pueblos un aire que recuerda a los del Atlas y otras zonas montañosas marroquíes.

\section{TeRrados, azoteas, galerías, balcones volados}

Los terrados están hechos con pesadas losas de piedras dispuestas horizontalmente y cubiertas con una gruesa capa de launa apisonada.

El terrado viene a ser algo sustancial en el paisaje urbano y en la propia vida del alpujarreño. En él se secan los frutos, se toma el sol, se realizan muchos trabajos domésticos, se hace vida familiar y de vecindad, bajo las típicas chimeneas. Es, pues, lugar de expansión y de comunicación con los vecinos.

Un rasgo distintivo de este tipo de edificio es la azotea o ático, construida en una porción del terrado y abierta al frente. BRENAN observa que en lo alto de las escaleras, cubriendo parte de la casa, hay un gran ático o azotea que se utiliza para almacenar grano y secar tomates y pimientos rojos, y que se comunica con el terrado o terraza, donde durante los meses de otoño e invierno se secan ma- 
zorcas de maíz, ristras de pimientos rojos, berenjenas cortadas y tomates.

Las casas que no tienen azotea, tienen, por lo general en la primera planta, una larga galería abierta que sirve para el mismo propósito.

En otras viviendas alpujarreñas hemos visto balcones volados o especie de puentes que cruzan las calles apoyándose en la casa del vecino. La mayor parte de estos balcones aparecen llenos de tiestos con flores.

\section{ORIENTACIÓN}

Todas las viviendas están orientadas al Mediodía, pues a 1.0006 1.200 metros de altitud gusta disfrutar de los rayos del sol. Están las casas como superpuestas unas encima de otras y con frecuencia se sale de una al tejado vecino.

\section{Semejanzas}

La arquitectura alpujarreña es primitiva y bereber. Así, observa Brenan que las casas de Yegen eran grises, en forma cúbica, de un estilo Le Corbusier, en rápido descenso por las laderas de las colinas y pegadas unas a otras. Los techos de grada, planos, y chimeneas humeantes sugerian algo construido por insectos.

Yegen alojaba unas mil personas en unas doscientas casas de dos pisos, todas construidas de piedra sin labrar y tierra. Las mejores tienen una tosca capa de argamasa. Los muros interiores están enyesados y encalados, pero en el exterior no se empleaba la cal. Eso era en tiempos de BRENAN, pues hoy se encala.

Ya hemos indicado anteriormente el origen de estas edificaciones. La casa antigua alpujarreña tradicional, la que heredaron los repobladores de los moriscos expulsados, había sido importada de la región del Atlas, sobre todo de Marrakech, donde en la actualidad conservan las mismas características.

Aunque este estilo de arquitectura únicamente se encuentra en Argelia y en el Atlas marroquí, la casa con azotea de la Región seca sudoriental española bien pudiera retroceder hasta la Edad del Bronce.

Algunos autores han visto también grandes semejanzas entre las construcciones alpujarreñas y las de las montañas iraquíes, donde 
la concepción urbanística es similar: casas escalonadas en las laderas de las montañas, azoteas de tierra impermeable, blancura de cal, paredes de piedra vista o con un revoque elemental, calles tortuosas, que sirven sólo para el paso, no para detenerse. La casa se arregla en el interior; lo importante es lo que constituye el bienestar íntimo de la familia, no lo que aparece al exterior.

\section{LA HISTORIA}

\section{Primeros pobladores}

La historia ha condicionado tanto como la geografía a esta Comarca.

Desde que llegué a las Alpujarras por todas partes me hablaban de leyendas de moriscos y de vestigios de otras épocas; por eso no he querido dejar de tratar el tema histórico, que he podido investigar tanto en los pueblos que he recorrido como en los libros que me han proporcionado en la biblioteca de Orgiva.

Parece ser que los primeros pobladores de la Comarca alpujarreña fueron los celtas, pueblos arios que tenían un patrimonio común y eran tribus de dólmenes. Hoy se da por seguro que los constructores de los dólmenes practicaban el culto de los muertos. Esto lo dice Joaquín Costa en su libro La religión de los celtíberos y su organización política y civil.

Por toda la Alpujarra han existido las llamadas "sepulturas de moros", formadas con piedras rectangulares. A pesar de su denominación, la procedencia de tales sepulturas se remonta a tiempos anteriores a los árabes y dentro de la Prehistoria.

También leemos en Costa que los celtíberos incineraban unas veces los cadáveres y otras los sepultaban en aquellas cámaras de piedra.

Es de suponer que el hombre del Neolítico español iría disputando al bosque y a las fieras los lugares habituales de esta Comarca, que, por su carácter montañoso, quedaría luego al margen de la cultura del cobre, llamada tartesia, que se expandió por todo el Sur, destacándose el poblado de Los Millares sobre el río Almería.

Los primeros relatos conocidos sobre los pobladorers de esta Comarca de las Alpujarras dicen que eran independientes y guerreros. Es natural que, como todos los montañeses, fueran más partidarios del bandidaje que del sometimiento a la autoridad. 
Es probable que los fenicios y los griegos hicieran acto de presencia en la Comarca, donde es tradición que estuvieron los cartagineses y que dejaron su huella en el Cerro de las Minas, próximo a Cáñar, donde buscaron sus metales.

Lugar curioso es la Cueva de los Murciélagos, cerca de Albuñol, donde había 69 cadáveres vestidos con túnicas, gorros y calzado de esparto. He observado la gran habilidad que tienen muchos alpujarreños para trabajar el esparto, y he leído que antes de la civilización de la madera hubo una civilización del esparto, pues es lógico pensar, y esto se ve en las aldeas de vida más sencilla, que antes de hacer una silla de madera se fabrica un asiento o escabel de esparto, y antes de fabricar un arca hacen un serón para meter sus cosas, dada la facilidad que tienen casi todos los campesinos para manejar y hacer la pleita, la soga y la tomiza.

En la mencionada Cueva de los Murciélagos se encontró un esqueleto que llevaba una gran diadema de oro. Otros cadáveres tenían hachas pulimentadas, cuchillos de pedernal y cerámica; por estas cerámicas han calculado los expertos que estos enterramientos pertenecen al final del cuarto milenio, y hay quien dice que si eso es cierto la diadema de oro encontrada en la Cueva de los Murciélagos es la pieza más antigua de oro labrado que se ha descubierto en Europa occidental.

\section{GRIEGOS, ROMANOS Y VISIGODOS}

BRENAN afirma que Ugijar es Odysseia o Ulysea, donde, según ESTRABÓN, había un templo dedicado a Atenas, en cuyos muros dejo Ulises sus escudos y los espolones de sus naves, en uno de sus viajes, como exvotos.

Ante la invasión de los romanos la Alpujarra opuso una fuerte resistencia.

Los visigodos vivieron o habitaron esta Comarca, como ya hemos visto por los vestigios desgraciadamente perdidos de la ermita de Capilerilla de Pitres.

\section{ARABES}

Todos sabemos que la conquista de España por los árabes a partir de su llegada, en el año 711, fue en la mayor parte de nuestra geografía un verdadero paseo militar, pero en otras, sobre todo en 
zonas muy montañosas, ya no hallaron tantas facilidades, sino, por el contrario, fuerte resistencia. Este es el caso de las Alpujarras, donde los musulmanes no lograron reducir a los cristianos sino cuando había pasado mucho tiempo. Por eso hay cronistas e historiadores árabes que llaman a los alpujarreños gentes muy belicosas, pues hicieron frente a los emires cordobeses e incluso coronaron por rey de la Alpujarra a Sawar ibn Hasum.

Después, al consolidarse el Califato, es lógico pensar que la mayor parte de la población alpujarreña eran cristianos que buscaban en esta Comarca refugio, pues ni los árabes ni los berberiscos, que podían habitar las mejores tierras, habrían de conformarse con unas montañas ásperas y frías. Esto explica que cuando Omar ibn Hafsún se lanzó contra los árabes, los alpujarreños le siguieron. Desde la Sierra de Ronda este caudillo famoso envió a las Alpujarras una guarnición mixta de muladíes (musulmanes españoles) y cristianos para defender el castillo de Juviles, por encima de Cádiar, que acabó siendo, sin embargo, tomado por Abderramán III, entonces joven califa, tras un asedio muy difícil, en el año 913.

Después de esta página histórica, las Alpujarras quedaron al margen de la Historia durante varios siglos.

Cuando se deshizo el Califato cordobés y se constituyó el primer Reino granadino, los alpujarreños hicieron valer su independencia bajo la tutela de su nuevo monarca, el príncipe Ben Hud, que reinó en toda Andalucía y que precisamente fue coronado en la villa alpujarreña de Ugijar. Durante el Reino musulmán de Granada, la Alpujarra dependió de la Provincia o Kora de Elvira, que abarcaba desde Gibraltar al Almanzora. Durante esta época, y mandando Aben Alhamar en las Alpujarras, se hicieron muchas obras, como por ejemplo cañerías para acequias de riego, manantiales que fueron transformando los barrancos alpujarreños en verdaderos jardines. Se fomentó la ganadería; se fabricó la seda y se explotaron las minas, abriéndose la Alpujarra al comercio y a la industria. La importancia de la seda fue tan grande en esta Comarca que un cronista musulmán la llamó Sierra del Sirgo (del latín sericum, seda).

Cuando los cristianos tomaron Sevilla muchos musulmanes se fueron al Reino de Granada, llegando a las Alpujarras multitud de bereberes acostumbrados a vivir en las montañas. La Alpujarra se berberizó. Así, la arquitectura de las casas y la distribución de los pueblos en barrios y cortijadas tomó la forma típicamente norteafricana. 
BRENAN, cuando veía a los alpujarreños que se tapaban la boca en invierno con una bufanda, incluso no haciendo mucho frío, sospechaba que era reminiscencia de una costumbre mora, pues los tuaregs del Sahara acostumbraban a llevar la boca tapada para evitar que entraran en ellos los espíritus malignos.

Durante los nazaritas granadinos los pueblos de las Alpujarras brillaron con gran lustre. Así pasó con Juviles, Andarax y otros muchos que, a lo ya dicho, unieron el cultivo de árboles frutales y había, aparte de la seda, una riqueza forestal, ganadera e incluso industrial. Así, cuando como consecuencia de la toma de Baza, amaneció un día súbdita de Castilla, y después de la toma de Granada por los Reyes Católicos residió en ella (en Andarax, Boabdil el Chico, último rey de Granada), pudo con razón escribirse lo que hemos leído en Hurtado de Mendoza en su Guerra de Granada contra los moriscos: "tierra estéril e aspera de suyo, sino donde hay vegas. Pero con la industria de los moriscos tratable e cultivada, abundante en frutos i ganados».

Tras la caída del Reino granadino, en las Capitulaciones de Granada, a Boabdil se le dejaron ciertos lugares en la Alpujarra para "poder vivir como rey". Al día siguiente de firmarse, en 1492, tales Capitulaciones, Boabdil y su familia tomaron la vía de la Alpujarra, tras entregar la ciudad y Reino de Granada al rey de Castilla.

Al año siguiente el rey pasó a Africa, abandonando la Alpujarra.

Con la llegada del Cardenal Cisneros a Granada se bautizaron la mayor parte de los moriscos alpujarreños, aunque seguían siendo moros en secreto.

Con cada intento de adaptar la sociedad alpujarreña a la sociedad cristiana, los árabes exigían el cumplimiento de las Capitulaciones de Granada, según las que se les garantizaba trato de mudéjares con plena libertad en su religión y costumbres. Todo esto motivó la repulsa en 1500 . Algunas personas, como el obispo de Guadix, estaban de parte de los moriscos, que aún seguían siendo dueños y señores de sus casas y haciendas.

Carlos V visitó Granada en 1526 y mandó que el obispo de Guadix y otros religiosos hiciesen una inspección para comprobar el estado de los lugares de los moriscos. Los clérigos dedujeron de su examen que mientras los moriscos se vistiesen y hablasen como moros conservarían la memoria de su secta y no serían buenos cristianos. 
El emperador parece ser que no prestó a esto atención, y se dice que por su negligencia los moriscos pudieron preparar la insurrección.

Todos sabemos la postura adoptada por Felipe II con las tolerancias y concesiones que habían tenido con los moriscos los Reyes Católicos y sus sucesores. Se dictó una pragmática en Granada, el primer día del año 1567, prohibiendo a los moriscos el empleo de armas, el uso de su lengua, el uso de baños, los cantares, músicas, fiestas y bodas a su usanza y sus reuniones íntimas. Obligándoles a vestir como cristianos, que las mujeres llevasen los ojos descubiertos, que las casas estuviesen abiertas viernes y sábados. Se trataba de desarticular las maniobras subversivas. Como los moriscos no respetaron esta pragmática se decretó su persecución, lo que pronto motivó la sublevación general de las Alpujarras, vega de Granada y Levante.

Los moriscos esperaban recibir socorro de Africa y eligieron por rey a don Fernando de Válor con el nombre de Aben-humeya. El levantamiento se centró en la Alpujarra, donde se extralimitaron en una lucha implacable que al final perdieron, siendo expulsados del Reino de Granada y trasladados a otras Regiones, como el valle del Guadalquivir y La Mancha. Tras la expulsión de los moriscos la Alpujarra, según escribe HuRTADo DE MENDOzA, quedó despoblada y destruida. Vino gente de toda España a poblarla y «dábanle las haciendas de los moriscos, con un pequeño tributo que pagan cada año".

Alarcón escribe: "Quedó el Reino de Granada tras la expulsión de los moriscos tan falto de población y de gente, que muchos lugares estaban yermos sin un solo vecino; y otros con tan pocos que no había quien cultivase los campos, hasta el extremo de que los arbolados y viñas se perdian por falta del beneficio ordinario y todo el trato y comercio estaba aniquilado".

Para aliviar tanta desolación Felipe II mandó a muchas ciudades una Real Carta con las instrucciones sobre la población que quería hacer nuevamente en el Reino de Granada con cristianos viejos por ser la tierra tan buena.

Para iniciar esta repoblación se enviaron comisarios a Galicia, Asturias, las montañas de Burgos y León, y los Reinos de Sevilla, Córdoba y Jaén, siendo muchas las familias que llegaron al Reino de Granada a costa de la Real Hacienda. 
En las Alpujarras había más de 48.000 moriscos y no quedó ninguno, despoblándose todos esos lugares.

En el Consejo y Junta de Granada, según escribe Manuel Gómez MORENo en un trabajo sobre la Alpujarra publicado en la revista Al Andalus, "se acordó poblar 259 lugares según la población que cada uno debía tener; se dispusieron otras tantas casas, señalando a cada uno tierra calma competente, viñas y arbolado, con título de suerte de población...».

Se hicieron provisiones de pan, harina, trigo, cebada y otras semillas, así como bueyes, caballos y mulas para el servicio de las nuevas poblaciones, todo ello a costa de la Real Hacienda.

Los nuevos pobladores llegaban de toda la Península, aunque más de las Regiones vecinas. Los gallegos no eran muchos, contra lo que realmente se ha creído. En el barranco de Poqueira llegaron 29 familias de Galicia, que se distribuyeron entre Capileira, Bubión y Pampaneira y otras aldeas ya desaparecidas. A la Alta Alpujarra llegaron también 137 gallegos, 208 andaluces, 104 castellanos y 34 extremeños.

En el valle de Almanzora no hubo gallegos y más de la mitad eran levantinos, y en el valle de Lecrín más del 46 por 100 procedian del valle del Guadalquivir, mientras el 28 por 100 venían de la Meseta y sólo el 11 por 100 de Galicia.

A pesar de esta repoblación no se llegó a la mitad de los que había antes de la guerra, y por eso desaparecieron muchos lugares moriscos.

El número de cristianos viejos, como se les llama en los libros de apeos, fue aumentado en tiempos de Felipe II; pero según se puede leer en el libro Antigüedad y excelencias de Granada, de Francisco BeRmúdez de PEdRAzA (Madrid, 1608), era tal la pobreza y mal acomodo de esta gente que pronto enfermaron más de 3.000 emigrantes, hasta tal punto que en 1593 el vecindario alpujarreño había disminuido de un modo alarmante y los supervivientes vivían en la miseria, apareciendo sus tierras poco cuidadas.

Esta decadencia continuó a lo largo de la primera mitad del siglo xvili, comenzándose con los Borbones un impulso renovador. Intensificándose el cultivo de la vid, de los olivos y de los almendros, hasta el punto que en tiempos de la invasión napoleónica la agricultura estaba muy extendida y la población había aumentado.

Ya en nuestro siglo un nuevo impulso experimentado por la Comarca ha sido debido a la acción del ministro alpujarreño don 
Natalio Rivas, que influyó para la creación de una red de carreteras que desbloqueó la Alpujarra. En 1936 esa red estaba casi terminada. Hoy llega a casi todos los pueblos alpujarreños. En la Geografía de España y Portugal de don Manuel TERÁn se habla de esto y de la impulsión que gracias a estas carreteras ha experimentado el comercio frutícola y la producción hortícola.

La población de Sierra Nevada (incluyendo los Municipios del Marquesado de Zenete) superará los 60.000 habitantes, pues ésta era la cifra en el Censo de 1960.

\section{LOS HOMBRES DE LAS ALPUJARRAS}

\section{Cómo SON LOS ALPUJARREÑOS}

Hemos visto que los alpujarreños eran gentes belicosas y con un marcado sentido de la independencia y de la libertad. Sobre todo, los habitantes de la Alpujarra Alta fueron siempre rebeldes a todas las imposiciones, incluso las legítimas, que parten del poder reconocido por ellos.

En cuanto al alpujarreño de hoy suele ser amante de su tierra, a la que vive apegado, cultivándola con las grandes dificultades que supone las montañas y su ambiente. No es raro ver a los campesinos alpujarreños trabajando de sol a sol y a veces regando a la luz de un farol o de la propia luna. En las labores campesinas suelen trabajar todos los de la casa, reservándose los hombres las faenas más duras, mientras las mozas se cubren la cabeza con pañuelos, los brazos con medias viejas y las piernas con pantalones para preservar la piel del sol mientras trabajan.

Hay una costumbre para ayudarse unos a otros en las épocas de más trabajo que se llama "torna peón», lo que significa que si tú trabajas hoy en lo mío, mañana trabajaré yo para ti.

Aunque la regla general es que el campesino alpujarreño trabaje en sus tierras y con sus ganados, también hay familias que bajan a la costa para colocarse en la recogida de la caña de azúcar y de las hortalizas de invierno y también para la vendimia.

De primavera a otoño viven en el cortijo, donde se trabaja con tal intensidad que apenas les queda tiempo para escuchar, algún que otro rato, la radio de pilas. La siega y la parva, que realizan normalmente como "torna peón", hacen revivir algo la familia. Los que realizan labores de vega llevan vida más confortable, ya que 
pueden tener un hogar con electricidad y más comodidad, y no como los que viven en los cortijos, que apenas ven más personas que sus familiares y vecinos. Estas familias sólo bajan a los pueblos una vez a la semana, por las cosas necesarias, durante el verano. En los meses de invierno, de diciembre a marzo, la mayor parte de los adultos tienen poco que hacer, aunque no por ello dejan de cuidar sus animales, dedicando mucho tiempo a un ocio improductivo y aburrido. Las clases pobres se reúnen en tabernas y bares, que abundan, pues en las más pequeñas aldeas hemos podido ver tres o cuatro de estos establecimientos.

El alpujarreño es sobrio en su comida. La vivienda y el mobiliario, aunque conservan su tipismo, son pobres.

A pesar de sus adversidades el alpujarreño es alegre y abierto con el forastero. Muchos están contentos del cambio de vida de estos últimos tiempos y recuerdan cuando calzaban alpargatas de esparto, cuando comían migas de maíz o las gachas o el puchero rebosante de grasa de cerdo.

Para la clase humilde, que es la más numerosa en la Alpujarra, el vínculo familiar es fuerte al estar presidido por la mujer, que suele ser recelosa y buena administradora, ejerciendo tal influencia sobre la familia que el propio cabeza de la misma le llama el ama, como ella llama el amo a su marido. (Yo pienso que si el alpujarreño es muy trabajador, también los moriscos tenían que serlo, pues ellos fueron los que construyeron las paratas para plantar vides incluso a 1.500 metros de altura.)

A pesar del apego del alpujarreño a su tierra, a veces sienten el encierro como un gran tormento y muchos emigran, aunque generalmente acaban regresando.

En las Alpujarras no se notan clases sociales, pero antes en cada pueblo había un cacique. Había también mucha rivalidad entre los barrios y aldeas. Todo esto está hoy superado, seguramente porque los alpujarreños que han salido al exterior han vuelto con una nueva manera de ver esta situación.

Nosotros creíamos que, dado el mucho tiempo que vivieron los moros en la Alpujarra, los alpujarreños responderían al tipo morisco, pero realmente no hay un tipo antropológico uniforme: en nuestro recorrido por los pueblos alpujarreños hemos visto personas rubias y morenas, dolicocéfalos y braquicéfalos, y también hemos visto muchos gitanos.

BRENAN escribía que los gitanos alpujarreños comían ranas, ser- 
pientes y lagartos o animales de granja que habian muerto de muerte natural.

\section{FOLKLORE}

El folklore alpujarreño es de lo más rico y variado. Las fiestas de Albondón, Trevélez y Válor, el desfile de los mosqueteros de Bezmar, las romerías (destacándose la de Orgiva) y sus bailes típicos son algunas de sus manifestaciones. Merecen destacarse las siguientes:

\section{A) Fiestas de moros y cristianos}

En el año 1492 se celebraron festejos en Roma para conmemorar la conquista de Granada por los Reyes Católicos, y entre otros actos tuvo lugar una función que representaba tan importante éxito de las armas cristianas. Todavía en muchos pueblos alpujarreños se celebran fiestas de moros y cristianos por personajes ataviados con trajes típicos de aquella época y suelen representar la conquista de los pueblos alpujarreños por las huestes de los Reyes Católicos y la rendición de los moriscos. De las fiestas de moros y cristianos tienen fama especialmente las de Válor.

\section{B) Rosarios de ánimas}

En algunos pueblos, como en los Bérchules, se celebraban «rosarios de ánimas" en las noches del invierno. Durante estas manifestaciones típicas religiosas se recorrían las pinas y tortuosas calles cantando oraciones ante las puertas de quienes así lo pedían.

\section{C) Bailes}

También en estos pueblos serranos eran famosos sus bailes, que alegraban las pequeñas plazas del lugar con la presencia policroma de las faldas tejidas por las mujeres alpujarreñas en los telares que abundaban en la Comarca y de los que aún queda algún ejemplar.

\section{D) Trobos}

En algunos pueblos de la Alpujarra Baja se celebran todavía los tradicionales «trobos", donde versificadores espontáneos componen 
estrofas con las que comentan hechos locales o ridiculizan a típicos personajes conocidos.

\section{E) Música}

Las guitarras, bandurrias, laúdes y violines son de uso en casi todos los pueblos, donde encontramos músicos de oído que a veces son verdaderos virtuosos. Aparte de los instrumentos de cuerda son también frecuentes el pandero y pandereta y el triángulo metálico, en todo lo cual queremos ver la influencia morisca.

\section{Del aislamiento al turismo}

Hasta que, poco antes del año 1936, empezaron a construirse las carreteras alpujarreñas, la incomunicación de esta Comarca era tan notoria que un alpujarreño pudo decir a Alarcón durante su viaje:

"A ver cuándo hacen ustedes aquí carreteras y ferrocarriles para que sepamos lo que es una rueda", y Alarcón escribe entonces: "Viejo hay en estos contornos que no ha visto en toda su vida ni un coche, ni una galera, ni un carro...; nada, en fin, que ruede, y el que ha visto esas cosas ha sido porque ha estado en Motril o Almería». Entonces la arriería tenía mucha importancia y los traslados se hacían en borrico, mulos y caballos, a veces empleando las ramblas y caminos de herradura. Las ramblas son los cauces fluviales que se quedan temporalmente secos, siendo entonces vías naturales.

De aquel afán arriero quedan todavía en la Alpujarra alguna venta que tuvieron mucha importancia y que solían estar en los caminos más transitados, pues en ellas hacían alto las diligencias y las recuas de mulas con que los arrieros llevaban el pescado de las playas de Motril, Salobreña y Calahonda a las aldeas alpujarreñas. También se veían en las ventas a los marchantes de ganados, a los recoveros y a las gentes de los cortijos vecinos.

Hoy ha desaparecido aquel aislamiento y la carretera llega hasta el más remoto de los pueblos montañeses. Puede entrarse en la Comarca por Granada, por Almería o por Motril. La carretera comarcal 332 cruza el valle de este a oeste, sirviendo de acceso tanto por Granada como por Almería. La comarcal 333 comunica la Alpujarra Alta con la Baja, saliendo a Albuñol, mientras la comarcal 331 une la Alpujarra con el Marquesado. 


\section{GEOGRAFIA ECONOMICA}

\section{LA PROPIEDAD DE LA TIERRA}

Dado el tamaño pequeño de la propiedad de la tierra y la intención del agricultor de sacar a esta propiedad el mayor partido, en los huertos y terrenos plantados de árboles frutales el suelo también se aprovecha para cultivos herbáceos, y se siembran patatas, habas verdes, maíz, etc., perjudicándose entre sí estos cultivos.

Tanto en la Alpujarra Alta como en la Media no es posible la mecanización del campo ni siquiera en las explotaciones de tipo medio, dadas las dificultades topográficas del terreno.

El grado de parcelación es muy variable. Hay lugares donde el propietario posee tres parcelas, mientras en otros llega a tener hasta 14 (Jorairatar y Turón).

De las 137.899 hectáreas que abarca la Región alpujarreña, 16.293 pertenecen al cultivo de cereal de secano, 5.927 al viñedo, 2.375 al olivar y 11.017 a los árboles frutales. El resto está ocupado por repoblaciones, prados y eriales.

El número de explotaciones es de 13.966, de las que sólo 41 superan las 200 hectáreas, habiendo 4.760 que no superan una hectárea. Las parcelas mayores de 300 hectáreas son en gran parte montes.

\section{Agricultura, FRUticultura y BOSQUES}

\section{A) Agricultura}

La agricultura alpujarreña, con un valor superior al de la ganadería y a las explotaciones forestales, constituye la base de su economía. El cultivo de cereales, que predomina claramente en la parte alta de la Comarca, cede terreno al viñedo en la Alpujarra Baja.

En la Alpujarra Alta se cultivan casi únicamente judías para grano, patatas y maíz, siendo las explotaciones familiares y de autoconsumo.

\section{B) Fruticultura}

No carece de importancia el cultivo de árboles frutales, como almendros, higueras y naranjos.

Como cordillera mediterránea su fruticultura es la de las orillas de este mar. Los típicos cultivos mediterráneos no suelen sobrepasar los 1.300 metros en la solana ni los 1.100 en la umbría, mezclán- 
dose en las partes más soleadas los viñedos con los olivos y nogales. Hasta 1.300 metros (umbría) y 1.800 (solana) llegan el castaño y la encina con las tierras sembradas de trigo y cebada en invierno, y maíz, patatas y habichuelas en el estío. En los valles más protegidos y soleados hay castaños, cerezos, manzanos, nogales y avellanos, siendo en las Alpujarras los castañares y robledales escasos y formando aisladas manchas en las que se mezclan con encinas, almendros e higueras.

Desde los 1.300 metros al norte y 1.500 metros al mediodía, los cultivos temporales de verano mezclados con las praderas llegan hasta los 2.000 y 2.400 metros.

En la Alpujarra Baja la higuera está en franca desaparición, mientras se plantan almendros en terrenos que se restan al viñedo. También adquiere importancia el cultivo de los agrios, sobre todo en los términos de Orgiva, Ugíjar y Cherín, en donde las continuas plantaciones se mezclan con los olivos. En estos dos últimos términos hay bastantes parrales.

En algunos lugares se inician plantaciones de melocotones y perales en palmeta.

En las Alpujarras se cultivan desde plantas tropicales, como el aguacate, el chirimoyo y el plátano, hasta las propias de los países nórdicos, como la sabina y la saxifraga e incluso el sauce de Laponia.

\section{C) Bosques}

Hay pocos bosques actualmente en las Alpujarras y las actividades madereras no existen. Se dice que toda la sierra estuvo cubierta de pinos, castaños y robles. Aún hay vestigios de bosques en algunos lugares, pero sólo en el fondo de los estrechos barrancos la vegetación es abundante y frondosa. La fobia al árbol de los repobladores castellanos que llevó Felipe II fue desastrosa. Hoy puede decirse que las masas arborescentes que se observan son fruto en gran parte de la repoblación forestal.

\section{VIDA DE MONTAÑA}

Generalmente no se hace vida de montaña en las Alpujarras, pues su agricultura no es de montaña. Aunque el alpujarreño sube a la montaña, lo hace sólo para cultivar sus pequeñas parcelas, en los "cortijos» o con el ganado. 
Acaso sea Sierra Nevada la única zona montañosa de Europa que carece de vida humana permanente. Tal vez gran parte de la culpa de esto la tuvieran los hombres llevados por Felipe II para repoblar la Comarca tras la expulsión de los moriscos, pues al querer implantar en la tierra las costumbres y cultivos de la meseta castellana, produjeron una intensa desarborización. Castilla no está, por desgracia, acostumbrada al árbol y los castellanos de entonces, para quienes era muy difícil dejar lo suyo para aceptar lo que los otros pueblos le ofrecían, no fueron capaces de asimilar el «medio» que iba a constituir su hábitat. Así se llegó, y se ha continuado en la Alpujarra, a una agricultura y una ganadería de "meseta», ahora en franca regresión.

Si en los años de superpoblación rural se pudo pensar en la conquista de nuevos terrenos para el cultivo, hoy todas las montañas de Europa están sufriendo una dispersión y emigración de sus pobladores. Los habitantes de los pueblos de montaña se están orientando hacia abajo.

La vida de montaña impone muchos sacrificios y renuncias al "confort» ofrecido por la civilización.

Mientras en las vegas de regadío no se pierde un palmo de terre. no, en la montaña cada vez se abandonan más las tierras de cultivo.

En el mismo Japón, que tanto ha evolucionado en la industrialización, se han olvidado de la colonización de la montaña.

\section{EL RIEGO}

De las 137.899 hectáreas que constituyen la superficie de las Alpujarras sólo se riegan 11.498 , siendo más intenso el riego en la Alpujarra Alta, donde depende de las nieves serranas y aparece dividida en los valles de los ríos diversos que allí tienen su nacimiento.

Tanto en el piso mediterráneo como en los más altos, cuando los campos o los pastos verdean al sol es porque la montaña está recorrida por acequias que aprovechan el agua de los barrancos, alimentados por los glaciares.

Como en el estío es muy intensa la sequedad y las altas temperaturas producen gran evaporación, el regadío es casi general y se hace a menudo imprescindible por todas partes. En las zonas donde el aprovechamiento agrario es difícil, el campesino construye sus 
típicos bancales y cultiva las pequeñas parcelas con mimos propios de jardinería.

En la parte baja de la Comarca, con importantes cultivos hortícolas, el regadío está muy limitado, siendo muchas veces sólo eventual.

\section{GANADERIA Y PASTOREO}

\section{A) Ganadería}

El ganado vacuno para carne se explota generalmente en plan familiar. De una a seis cabezas en la parte Alta y de dos a cinco en la Media Alpujarra. Suele ser de raza retinta, poco precoces, pero resistentes al clima extremo en que viven.

El vacuno de leche manifiesta tendencia a aumentar, pero hoy es escaso, salvo en Lanjarón. Este ganado está prácticamente estabulado.

El ganado de cerda, también estabulado y generalmente en explotaciones familiares, es en gran parte de raza ibérica, que se tiende a sustituir por cruce de razas blancas y del país.

La cabaña ovina, muy atomizada, se hallaba en decadencia.

El caprino, en manos de clásicos cabreros, se distribuye en rebaños de 30 a 40 cabezas.

\section{B) Pastoreo}

En verano los cultivos temporales están ligados a la ganadería, pero el pastoreo está escasamente desarrollado, quizá, dada la gran sequedad estival.

El ganado porcino aparece estabulado.

El ganado vacuno de algunos Municipios altoalpujarreños busca en verano los pastos de altura.

El ganado lanar realiza una trashumancia estival entre la costa y la sierra, que va desde mayo a fines de octubre. Los rebaños suben hasta los pueblos más altos acompañados por numerosas familias que se van esparciendo por "cortijillos" con sus animales de labor, dedicándose a cultivar durante esos meses el centeno y las patatas.

En septiembre se inicia el descenso, deteniéndose un mes el ganado en los primeros núcleos permanentes de población, donde des- 
cansa y estercolea los campos que se sembrarán de trigo. En noviembre los rebaños bajan a la costa para invernar.

\section{CAZA Y PESCA}

\section{A) Caza}

La caza que puede tener más interés en toda la Sierra Nevada es la de las cabras montesas.

Hay quien piensa que hoy las cabras montesas de Sierra Nevada emigran a las sierras de la Contraviesa o a la Alpujarra cruzando entre los campos sembrados de patatas y hortalizas, naranjales, etcétera. Eso podría ocurrir hace unos siglos cuando había menos vegas cultivadas y las sierras estaban más solitarias. Hoy parece menos verosímil.

Para la caza de las cabras montesas se requiere cualidades excepcionales: facultades físicas, paciencia, amor a la naturaleza, sobre todo a la sierra.

De los tipos o modalidades de caza "batida" y "aguardo" o "rececho", este último debe ser el estilo de caza de las montesas. Es para ello la mejor época la del celo del mes de mayo.

Las montesas no se hayan generalmente en la Alpujarra, sino en las escarpadas laderas del Mulhacén y de la Alcazaba, por ejemplo.

\section{B) Pesca}

Está legalmente autorizada con caña. Se adoptan los más variados modelos y técnicas, con diversos tipos de anzuelos, cebos y senuelos. La talla mínima de las capturas ha de $\operatorname{ser} 19 \mathrm{~cm}$. y pueden verificarse en los tramos bajos de los ríos entre el primer domingo de marzo y el 15 de agosto, y en las zonas de alta montaña entre los días 16 de mayo y 30 de septiembre.

Los ríos trucheros dan a ambas vertientes, mediterránea y atlántica.

Los ríos de la vertiente mediterránea son: el río Lanjarón, el Chico, el Poqueira, el Trevélez, el Grande y el Chico de Bérchules.

Los de la vertiente atlántica son: el río Genil y sus afluentes 
hasta Granada: Aguas Blancas, Monachil y Dilar, y los ríos Alhoris, Darro y Fardes.

La trucha arco iris está localizada en los ríos Aguas Blancas y Fardes, en el lugar denominado El Molinillo.

\section{INDUSTRIA}

En minería es de destacar la actividad del cerro del Conjuro. Su explotación, detenida a principios del siglo, ha sido últimamente puesta en marcha por la Siderúrgica de Avilés. Algunos años las extracciones de mineral han sobrepasado las 200.000 toneladas métricas, que hoy son remitidas por el puerto de Motril hasta la costa cantábrica. Con este renacer de la minería alpujarreña se ha logrado decuplicar el movimiento portuario de Motril.

En cuanto a la energía eléctrica es bien sabido que de ella se benefician sobre todo las Comarcas no serranas. En el caso de la vertiente septentrional de Sierra Nevada se beneficia Granada capital.

Dentro del marco de la sierra, el río Poqueira es el que produce más energía hidroeléctrica de la Provincia con la central de la Cebadilla, de 13.000 KW., y la de Pampaneira, con $16.000 \mathrm{KW}$. Esta potencia instalada se ve reducida por los fuertes estiajes de verano.

En la Alpujarra Baja se cultiva bastante la vid y existen muchas industrias familiares de transformación en vinos. La falta de una técnica adecuada y el desconocimiento de tratamientos, trasiegos, aclareos, etc., hace que este vino no presente un aspecto muy claro, aunque su calidad y graduación sean buenas. Gran parte de la producción se envía a La Mancha y a Jerez de la Frontera, aunque existe una bodega con planta embotelladora en Albondón, que tiene una capacidad suficiente para absorber una importante producción total de la uva y del vino alpujarreño.

En otros tiempos abundaban los telares manuales en las Alpujarras. Hoy aún queda alguno funcionando como una reliquia, de donde surgen los típicos tejidos de polícromas figuras caprichosas que prestigian la artesanía alpujarreña.

Hay sólo una pequeña industria en toda la Alta Alpujarra: se trata de la ya mencionada fábrica de alfombras alpujarreñas ubicada en los Bérchules. 


\section{Problema de emigración}

Aunque el alpujarreño es muy amante de su tierra, hay bastantes que han emigrado, si bien la mayoría suele regresar.

En la Comarca hubo épocas de mucha emigración, como, por ejemplo, cuando en 1880 la plaga de la filoxera destruyó las viñas alpujarreñas. Entonces se inició una emigración a Sudamérica, que redujo la población a la mitad. Después el censo volvió a crecer en 1920.

\section{EXCURSIONES PARA CONOCER LA COMARCA}

Por la carretera general Bailén-Motril, desviándose por el puente de Tablate, se entra en Lanjarón y luego en Orgiva. Desde allí se pueden hacer excursiones para conocer la Comarca. Sobre Orgiva se levanta la Sierra de Lújar. Una carretera se desvía a la entrada de Orgiva y sube una cuesta muy empinada hasta el cruce de Cáñar, desde donde se contempla la vega. La carretera está bien asfaltada y las curvas son muchas. Algunos pueblecillos, como Cánar, Soportújar y Caratauna, quedan fuera de la carretera general. El barranco de Poqueira nos muestra en su solana tres alegres pueblecitos: Pampaneira, Bubión y Capileira, que suben hacia el Veleta. Bajando otra vez desde Capileira y siguiendo la carretera hacia Ugijar aparece a pocos kilómetros Pitres, y a sus pies, Mecina-Fondales, adonde se llega descendiendo por una carretera asfaltada de poco más de dos kilómetros. Más allá, otras dos aldeítas, Alabaitar y Ferreirola, que aún tienen mala carretera. Volviendo otra vez a la carretera que va a Ugijar se pasan las minas de hierro del Conjuro y después aparece Pórtugos, y pasada la ermita de Nuestra Señora de las Angustias se puede beber el agua ferruginosa de su famoso Chorreón.

Busquístar se asoma a la carretera que sube a Trevélez, adonde se llega poco después observando sus tres barrios que se escalonan como si quisieran ganar las faldas del Mulhacén.

Aquí puede terminar una primera excursión y desde Trevélez regresar a Orgiva.

Otro día se puede llegar a Juviles doblando la carretera por el cerro del Conjuro, y desde la cruz de Juviles, subiendo hacia los Bérchules por la Sierra de la Contraviesa, se puede ver a los pies 
Cádiar, Narila y Lobras. Después de pasar Mecina-Bombarón, habiendo dejado atrás Válor, se llega a Ugijar, de donde parten autobuses para Granada. Desde Ugíjar se puede subir por Cherín y Laroles hasta La Calahorra, pues no habiendo nieve se cruza la sierra por el Puerto de la Ragua.

Otra excursión puede ser la de la Alpujarra Baja. Partiendo desde Orgiva hacia Motril por Vélez de Benaudaya. Desde Motril hasta la Rápita, cerca de Albuñol, se recorre gran parte de la costa alpujarreña y de trecho en trecho se ven torres de defensa. Desde cada una de ellas se ven otras dos. Durante el trayecto se pueden admirar castillos, como el de Castelldeferro.

Llaman la atención a lo largo de este recorrido muchos cobertizos de plástico que afean el paisaje, pero que no dejan de ser prácticos puesto que son cultivos enarenados. Desde la Rápita se sube a Albuñol por la rambla, donde hay una gran extensión de estos cultivos.

Subiendo desde Albuñol por la carretera 333 se van dejando atrás algunos pueblecitos tales como Sorvilán, Polopos y Rubite, a la izquierda, y Alcázar y Fregenite, a la derecha. Desde Sorvilán se ve el Mediterráneo, que está a pocos kilómetros. Una carretera lo une con la playa de la Mamola.

Ya en la carretera 332 y próximo a Orgiva, a la mano derecha en la hondonada, descansa el pueblo de los Tablones.

Culminando la rambla de Albuñol se ve la antigua venta llamada Haza del Lino, en cuyas proximidades hay un secadero de los famosos jamones alpujarreños.

Los pueblecitos mencionados no se encuentran a la orilla de la carretera 333 , sino a diversos kilómetros de la misma, pero todos cuentan con carretera asfaltada, aunque alguna con muchas curvas.

Durante toda esta excursión se ven muchas viñas y almendros.

Se puede salir de la Comarca siguiendo, desde Orgiva, la carretera 332 y recorriendo la Alpujarra Media. Se pasa por Torviscón, Cádiar, Yátor y Ugíjar, desde donde se sale por Cherin a la Alpujarra almeriense, y se pasa por Lújar de Andarax, que conserva el recuerdo de Boabdil y de Aben-Humeya.

Algunos pueblecitos no cuentan con carretera asfaltada, sino con caminos vecinales, como Notáez, Cátares, Nieles, Timar y Lobras, que forman una bolsa incomunicada situada en la parte central de las carreteras 332 y 333. 


\section{BIBLIOGRAFIA}

Alarcón, Pedro-Antonio de: La Alpujarra, 5.a ed., Madrid, 1972.

Bermúdez DE PEDRAZA, Francisco: Antigüedad y excelencias de Granada, Madrid, 1608.

BRENAN, Gerald: Al sur de Granada, Editorial Siglo XXI.

CARo Baroja, Julio: Los moriscos del reino de Granada, Madrid, 1960.

CARrascosa, Miguel: A las puertas de la Alpujarra, Granada, 1960.

CONDE, José-Antonio: Historia de la dominación de los árabes en España, Barcelona, 1884.

Costa, Joaquín: La religión de los celtíberos y su organización politica y civil, Madrid, 1917.

FERNÁNDEZ y GonZÁLEZ, Manuel: Los monfies de la Alpujarra, Madrid, 1856.

GARRIDO ATIENZA: Capitulaciones.

Gómez Moreno, Manuel: "De la Alpujarra», en la revista Al Andalus, tomo XVI, año 1951.

HURTADO DE MENDoza, Diego: Guerra de Granada que hizo el rey don Felipe II contra los moriscos de aquel reino, sus rebeldes. Oficina de Benito Mongfort, Valencia, 1776.

JANER: Condición social de los moriscos en España, y BoRONAT y BarRaChina, Pascual: Los moriscos españoles y su expulsión, dos volúmenes, Valencia, 1901.

LAFUENTE AlCANTARA, Miguel: Historia de Granada, comprendiendo las de sus cuatro provincias, Almería, Jaén, Granada y Málaga, cuatro volúmenes, Granada, 1843-1848.

LóPEZ MÉNDEZ, Harold: España desconocida. La Alpujarra. Rincón misterioso. Prólogo de Caro Baroja, Madrid, 1967.

Mámol. y Carvajal, Luis de: Historia de la rebelión de los moriscos del reino de Granada, Málaga, 1600.

Rufo, Juan: La Austriada, Biblioteca de Autores Españoles, XXIX. TERÁN, Manuel: Geografía de España y Portugal. 
REVL-1982, núm. 215. GUERRA-LIBRERO Y ARROYO, GUMERSINDO. LAS ALPUJARRAS (ESTUDI...

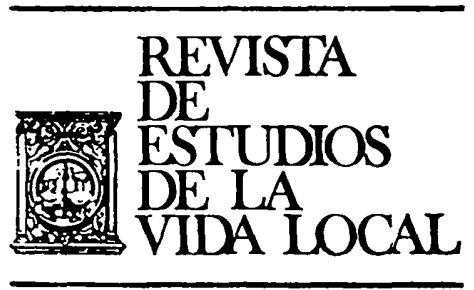

\section{ESTADISTICA}


REVL-1982, núm. 215. GUERRA-LIBRERO Y ARROYO, GUMERSINDO. LAS ALPUJARRAS (ESTUDI...

REVL-1982, núm. 215. GUERRA-LIBRERO Y ARROYO, GUMERSINDO. LAS ALPUJARRAS (ESTUDI... 